\title{
Evidence of TAU pathology in kaolin-induced hydrocephalus model of the aged rat
}

\author{
Petra M Klinge*1, Anna Heile ${ }^{1}$, Stephanie Slone ${ }^{2}$, Conrad E Johanson², \\ Miles Miller ${ }^{2}$, John A Duncan III ${ }^{2}$, Thomas Brinker ${ }^{1}$ and Gerald D Silverberg ${ }^{2}$
} \author{
Neuroscience, Brown Medical School, Providence, Rhode Island 02903, USA \\ Email: Petra M Klinge* - pmklinge@gmail.com \\ * Corresponding author \\ from 52nd Annual Meeting of the Society for Research into Hydrocephalus and Spina Bifida \\ Providence, RI, USA. I I-I4 June 2008 \\ Published: 3 February 2009 \\ Cerebrospinal Fluid Research 2009, 6(SuppI I):S37 doi:I0.II86/I743-8454-6-SI-S37
}

Address: ${ }^{1}$ Department of Neurosurgery, International Neuroscience Institute, Hanover 30625, Germany and ${ }^{2}$ Department of Clinical

This abstract is available from: http://www.cerebrospinalfluidresearch.com/content/6/SI/S37

(c) 2009 Klinge et al; licensee BioMed Central Ltd.

\section{Background}

Accumulation of A-beta peptides and hyperphosphorylated Tau (hpTAU) has been observed in immunohistochemical (IHC) studies of kaolin-induced hydrocephalus in the aged rat. Defective clearance via CSF and altered transport via blood brain barrier receptor expressions was suggested to be causal [1]. The present study reports further evidence to the significance of A-beta and TAU pathology as disease mechanisms in hydrocephalus using quantitative A-beta and hpTAU ELISA in addition to IHC studies of the lipid oxygenase 12/15 enzyme (LOX12/15), a marker of the cytokine-induced inflammation in Alzheimer disease (AD).

\section{Materials and methods}

In nine 12 month-old Sprague-Dawley (SD) rats with kaolin-induced hydrocephalus, A-beta 40 and 42 and hpTau pT231 ELISA was performed at 2, 6 and 10 weeks post induction (3 age-matched controls) in cortical plus subcortical tissue homogenates. Specific LOX12/15 (1:1000, BIOZOL/CAYMAN) IHC was performed in another 20 animals ( 5 controls) at the same time points including double-label fluorescent IHC using CY2 and CY3 conjugated secondary antibodies for co-localizations of A-beta 42, LOX12/15, hpTau pT231 and hpTau AT100.

\section{Results}

A-beta 42 and 40 ELISA shows a significant increase over the course of hydrocephalus at 6 and 10 weeks postinduction when compared to the controls, e.g., A-beta 40 (pg/mg): $9.7 \pm 1.3$ and $9.5 \pm 0.5(6,10 \mathrm{wk})$ vs. $3.2 \pm 1.2$ (controls); $\mathrm{p}<0.01$ (ANOVA). HpTAU pT231 ELISA increased at $10 \mathrm{wk}$ post-induction to $56.4 \pm 17.3$ from $28.5 \pm 17.2 \mathrm{pg} / \mathrm{mg}$ in controls $(\mathrm{p}<0.01)$. In hydrocephalus, LOX12/15 positive staining appeared in both cortical and hippocampal neurons, in glial processes (near vessels) and in hippocampal microglia-type cells. Image analysis (CellFं, OLYMPUS) revealed an increased number of LOX12/15 positive particles in the cortex of the hydrocephalic animals compared to controls ( $\mathrm{p}<0.05$, unpaired t-test). Extracellular AT100 was clearly co-localized with the A-beta 42 around hippocampal vessels, while hpTAU pT312 IHC showed intraneuronal co-localisation at areas with "condensed excess" Tau. Intraneuronal A-beta 42 as well as pT231 was further co-localized with LOX12/15 in some cortical regions.

\section{Conclusion}

The findings of a 3-4 fold increase in A-beta is consistent with the amyloid burden in patients with early AD (Braak I). The increase in the amount of hpTAU at $10 \mathrm{wk}$ as well as the co-localization pattern of the hpTAU markers with the A-beta supports that A-beta accumulation induces TAU pathology. LOX12/15 findings add further evidence 
that the aged hydrocephalic rats might be a valid model for investigating the NPH/AD pathophysiological continuum.

\section{References}

I. Klinge PM, Samii A, Niescken S, Brinker T, Silverberg GD: Brain amyloid accumulates in aged rats with kaolin-induced hydrocephalus. Neuroreport 2006, 17:657-660.

Publish with Biomed Central and every scientist can read your work free of charge

"BioMed Central will be the most significant development for disseminating the results of biomedical research in our lifetime. " Sir Paul Nurse, Cancer Research UK

Your research papers will be:

- available free of charge to the entire biomedical community

- peer reviewed and published immediately upon acceptance

- cited in PubMed and archived on PubMed Central

- yours - you keep the copyright 